\title{
Effects of Plastic Film Mulching on Quality and Appearance of Statuma Mandarin Fruit
}

\author{
Guifu Zhang1,2, Shenxi Xie1 \\ ${ }^{1}$ Horticulture \& Landscape College, Hunan Agricultural University, Changsha, China \\ ${ }^{2}$ Nuclear Technology and Chemical \& Biological College, Hubei University of Science and Engineering, Xianning, \\ China \\ Email: 517584801@qq.com
}

Received 30 October 2014; revised 29 November 2014; accepted 8 December 2014

Copyright (C) 2014 by authors and Scientific Research Publishing Inc.

This work is licensed under the Creative Commons Attribution International License (CC BY). http://creativecommons.org/licenses/by/4.0/

(c) (7) Open Access

\begin{abstract}
Six-year Statuma mandarin (Citrus unshiu Marc. Cv. Miyagawa Wase) trees were used as materials to investigate the effects of plastic film mulching on quality and appearance of Statuma mandarin fruit during three periods of cell division, cell enlargement and mature stages. The results showed that mulching during the cell division and early-mature stages increased total sugar and reduced sugar content of fruit as well as the Vc content, compared to the control. However, the titratable acid content, fruit size, peel weight and single fruit weight were all lower than the control. Film mulching during the cell division phage resulted in higher edible fruit rate, while the fruit shape index was similar to the control. Mulching during the early-mature stage didn't affect the edible rate of fruit, but caused lower fruit shape index. Compared to the control, film mulching during the cell enlargement period caused lower total and reducing sugar content, titratable acid content and edible rate, while the Vc content was a little bit higher than the control. In addition, the fruit size, peel weight, single fruit weight and fruit shape index were all lower than the control. Mulching during the early-mature period effectively enhanced the content of total and reduced sugar and Vc and decreased the titratable acid content. Hence, it increased fruit quality but had negative effect on fruit appearance.
\end{abstract}

\section{Keywords}

Statuma Mandarin, Film Mulching, Fruit Quality, Fruit Appearance

\section{Introduction}

China is one of the main countries for citrus production and has No. 1 harvest area and No. 2 citrus production in the world [1]. The south hilly regions have rich light, heat and biological resources and the production poten- 
tial is high. Therefore, these regions are the main citrus production area in China. However, more than $50 \%$ area is hillock land. Citrus is easily affected by water stress, which influences citrus yield and quality together with seasonal drought [2]. Plastic film mulching affects soil in different ways. It can increase soil temperature, have effect on water conservation and avoidance, enhance soil fertility and improve soil physical properties, so it has important impact on crop growth, development, yield and quality [3]. Studies show that mulching efficiently increases fruit sugar when citrus is mature. However, its effect on acid accumulation is controversial [4]-[8]. Currently, there are a lot of studies focusing on the effect of plastic film mulching on fruit quality, soil environment and light under the canopy [5]-[8], but studies on the effect of mulching on fruit appearance and quality during citrus fruit development are much less. In the present study, we used Statuma mandarin trees to investigate how film mulching during various stages affects appearance and quality of citrus fruit.

\section{Materials and Methods}

\subsection{Materials}

The experiment was performed in the citrus garden of Jishou, Hunan. Six-year Statuma mandarin (Citrus unshiu) trees were used as materials. Four trees whose growth and fruit amount were similar were selected for film mulching (distance: $1.5 \mathrm{~m} \times 3.7 \mathrm{~m}$ ). Four adjacent trees without mulching were used as controls. The treatment was performed on July 15th, 2011 (A, cell division phage of fruit), August 15th (B, cell enlargement stage) and September 15th (C, early-mature period), respectively. The double silver-black reflective film for mulching was from Jiangsu Mikedo Farm Plastic Film Ltd. The mulching ranged over $0.5 \mathrm{~m}$ of the canopy dripping line. After mulching, 4 fruits were randomly taken from different direction every $15 \mathrm{~d}$.

\subsection{Methods}

After film mulching, a curved thermometer (Hebei Wuqiang Instrument Factory) and a soil tensiometer (TEN40, Zhejiang Tuopu Instrument Ltd. Company) were set up $25 \mathrm{~m}$ and $40 \mathrm{~m}$ below the soil surface, respectively. Soil temperature and water potential results were collected on the sampling date from 8 am to $9 \mathrm{am}$.

The method proposed by Xuyan Lu et al. [9] was used to detect total and reducing sugar, titratable acid and Vc content of fruit. Fruit longitudinal and traverse diameters and peel thickness were measured using 1/1000 cm vernier caliper measurement and the accuracy was $0.01 \mathrm{~cm}$. Fruit weight was determined using 1/100 electronic balance measurement and the accuracy was $0.01 \mathrm{~g}$.

The SPSS software and the LSD method were used to analyze data. The Sigma Plot 10.0 software was used to make charts.

\section{Results and Discussion}

\subsection{The Effect of Film Mulching on Soil Temperature and Water Potential}

The results showed that film mulching increased soil temperature and reduced soil water potential (Figure 1). After mulching treatment, the soil temperature in the $25 \mathrm{~cm}$ region reached a peak on August 30th. It was about $2^{\circ} \mathrm{C}-3^{\circ} \mathrm{C}$ higher than the control (Figure 1(a)). However, the water potential in the $40 \mathrm{~cm}$ region became lower than the control five days after mulching and reached the lowest potential on September 30th. Generally, it was about 15 - $-10 \mathrm{kP}$ a lower than the control (Figure 1(b)).

\subsection{The Effect of Film Mulching on Fruit Quality}

\subsubsection{The Effect of Film Mulching on Total and Reducing Sugar Contents of Fruit}

The results indicated that the accumulation trends of total sugar were similar between the treated and control trees during citrus fruit development (Figure 2). Before August 30th, the accumulation was fast. From August 30th to September 15th, the accumulation speed had a reducing trend, which may be due to high temperature stress. After September 15th, the accumulation was sharply increased. If film mulching was performed during the cell division phage (A), the total sugar content before September 6th was higher than the control; it was lower than the control between September 6th and October 15th; and it became higher than the control after October 15th. If film mulching was performed during the cell enlargement period (B), the total sugar content was lower than the control before September 30th and became higher than the control. It was a little bit lower than 


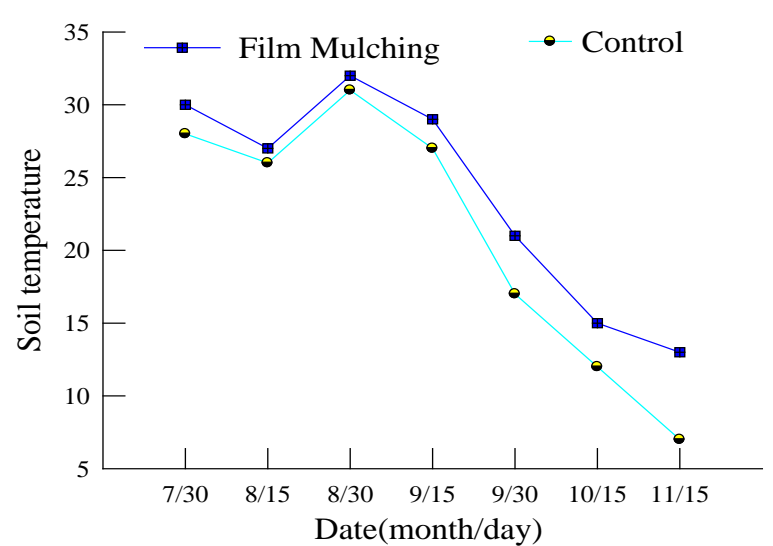

(a)

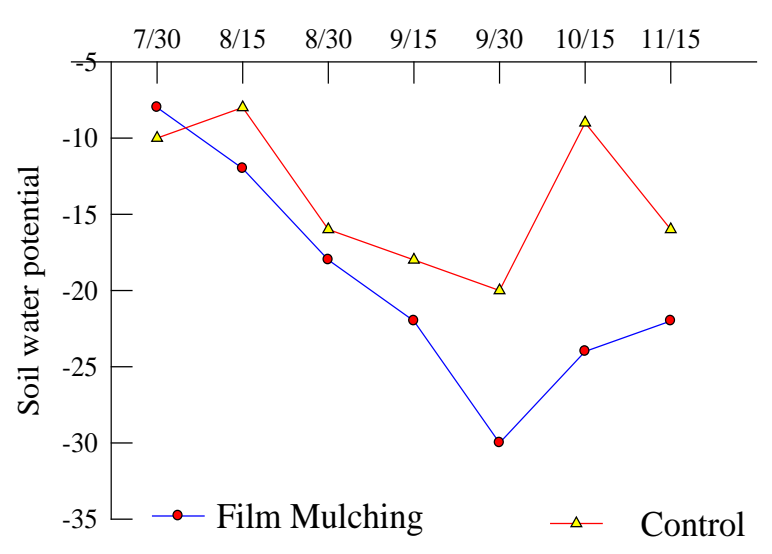

(b)

Figure 1. Effect on soil temperature (a) and soil water potential (b).

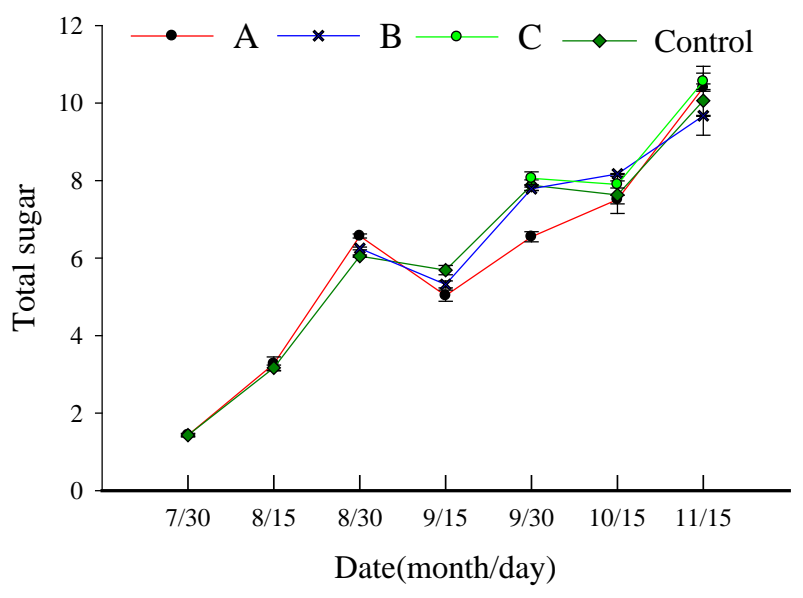

Figure 2. The effect of film mulching during different periods on total sugar content of fruit.

the control during the mature period. If film mulching was done during the early-mature period (C), the total sugar content was higher than the control.

The results indicated that the accumulation of reducing sugar had two peaks during citrus fruit development (Figure 3). It reached a small peak on August 15th, and the big peak showed up on September 30th. If film mulching was performed during the cell division phage (A), the reducing sugar content was similar to the control before August 15th; it was lower than the control between August 15th and September 20th; and it became higher than the control after September 20th. If film mulching was performed during the cell enlargement period (B), the reducing sugar content was always lower than the control before August 15th and it was significantly higher than the control around September 30th. However, it was lower than the control after October 15th. If film mulching was done during the early-mature period (C), the reducing sugar content showed no difference within one month after mulching and was higher than the control in the late stage (after October 15th).

\subsubsection{The Effect of Film Mulching on Titratable Acid and Vc Content of Fruit}

The results implicated that the titratable acid changes during citrus fruit development were different between the treated and control trees (Figure 4). The control tree showed two peaks. It reached a small peak on August 15th, and the big peak showed up on September 15th. However, the film mulching trees only had one peak. If film mulching was performed during the cell division phage (A), the titratable acid content was similar to the control before August 15th; it was higher than the control between August 15th and October 30th; and it became lower than the control after October 30th. If film mulching was performed during the cell enlargement period (B), the 


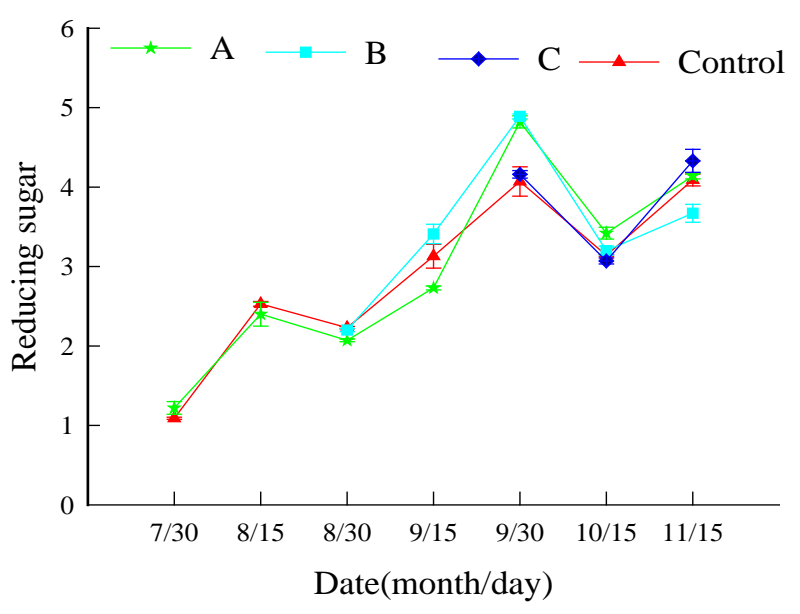

Figure 3. The effect of film mulching during different periods on reducing sugar content of fruit.

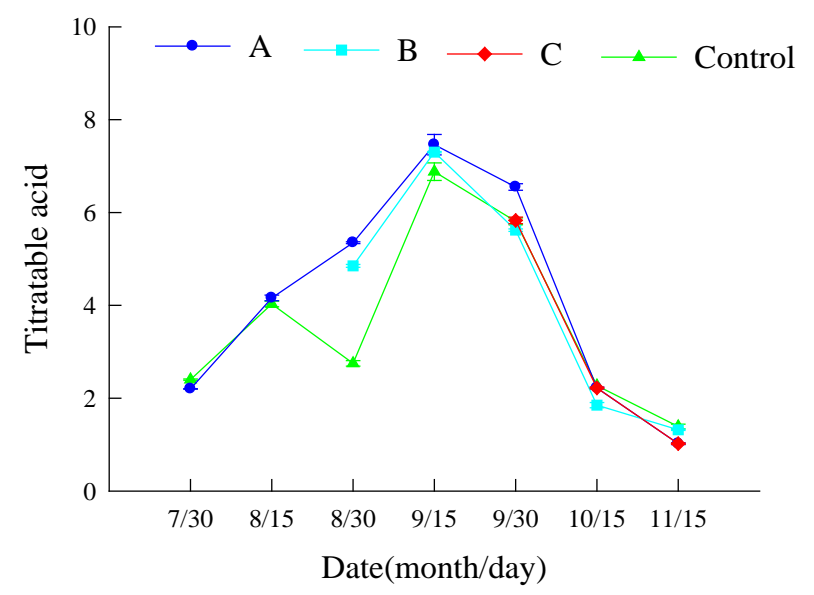

Figure 4. The effect of film mulching during different periods on titratable acid content of fruit.

titratable acid content was always higher than the control within one and a half months after mulching, and became lower than the control. If film mulching was done during the early-mature period $(\mathrm{C})$, the titratable acid content showed no difference between the treated and control trees within one month after mulching and later, it was always lower than the control.

The results indicated that the changing trends of Vc content were similar between the treated and control trees during citrus fruit development (Figure 5). Before September 30th, the Vc content was stable, about 44 $\mathrm{mg} / 100 \mathrm{ml}$. After September 30th, it was sharply increased. If film mulching was performed during the cell division phage (A), the Vc content was similar in the early period and was slightly increased in the late period. If film mulching was performed during the cell enlargement period (B), the Vc content was higher than the control. If film mulching was done during the early-mature period (C), the Vc content was obviously higher than the control.

\subsubsection{The Effect of Film Mulching on Edible Rate of Fruit}

The results indicated that the changing trends of edible rate were similar between the treated and control trees during citrus fruit development (Figure 6). On August 15th, the edible rate of fruit reached a small peak and it was decreased after the peak. It was increased after August 30th and became stable after September 30th. If film mulching was performed during the cell division phage (A), the edible rate was lower than the control before August 20th (the early stage); it was higher than the control between August 20th and September 10th; and it 


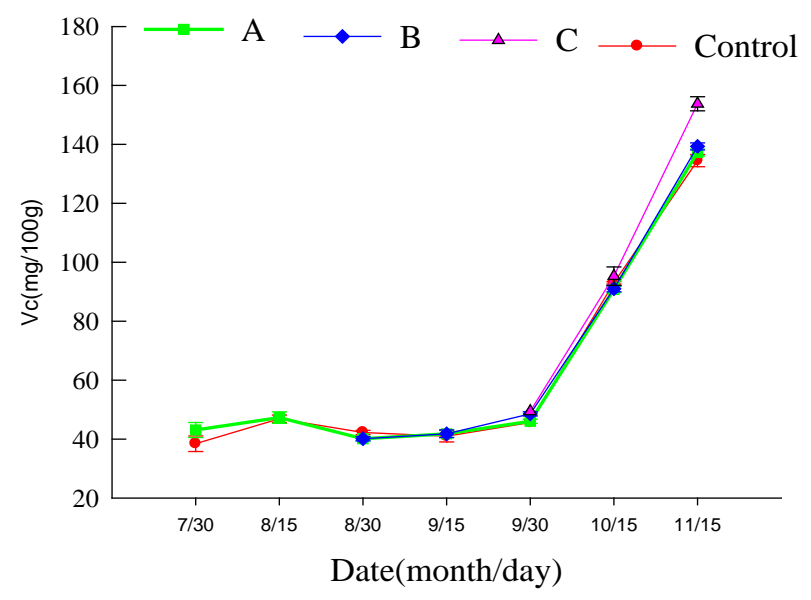

Figure 5. The effect of film mulching during different periods on Vc content of fruit.

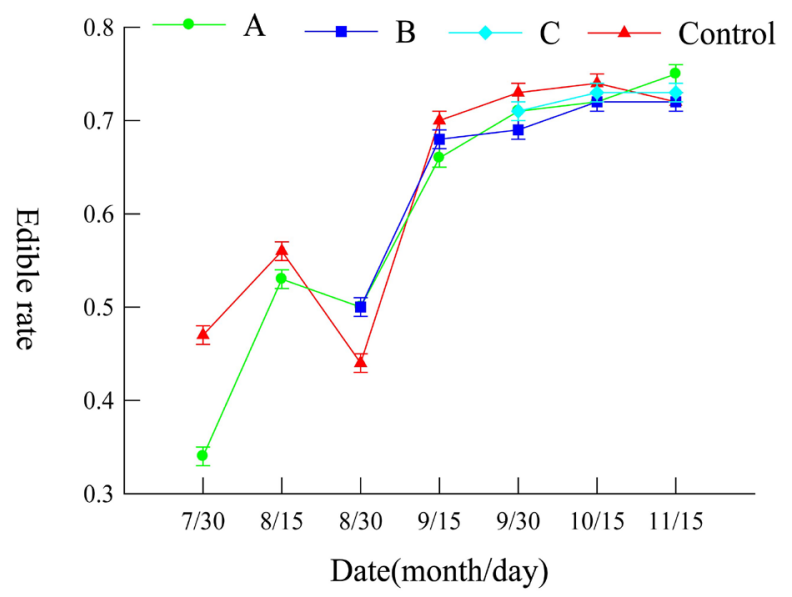

Figure 6. The effect of film mulching during different periods on edible rate of fruit.

was similar to the control after September 10th (the late stage). If film mulching was performed during the cell enlargement period (B), the edible rate was higher than the control in the early stage and lower than the control in the late stage. If film mulching was done during the early-mature period (C), the edible rate had no difference between the treated and control trees.

\subsubsection{The Effect of Film Mulching on Fruit Appearance}

We detected the effect of film mulching during different periods on five fruit appearance indexes like longitudinal diameter, transverse diameter, etc. (Table 1). The results showed that film mulching influenced fruit appearance during citrus fruit development. Among these five indexes, the longitudinal of treat A and B were all smaller than the control after mulching treatment. Before the end of cell enlargement period, the peel weight was significantly higher than the control (except the weight on August 15th). It was obviously lower than the control after enlargement period. The single fruit weight was dramatically lower than the control (except the weight on August 30th). However, the fruit shape index of different treatments was similar.

\section{Discussions}

\subsection{The Effect of Film Mulching on Soil Temperature and Water Potential}

In the present study, we detected the changes of soil temperature and water potential after plastic film mulching. 
Table 1. The efffect of film mulching during different preiodson fruit appearance.

\begin{tabular}{|c|c|c|c|c|c|c|}
\hline Sampling date & Mulching & $\begin{array}{l}\text { Longitudinal } \\
\text { diameter/mm }\end{array}$ & Transverse diameter/mm & Fruit shape index & Peel weight/g & $\begin{array}{l}\text { Single fruit } \\
\text { weight/g }\end{array}$ \\
\hline \multirow{2}{*}{ July 30th } & A & $27.83 \mathrm{~b}$ & $28.88^{*}$ & 0.96 & $8.75 a$ & 13.34 \\
\hline & control & 29.86a & 29.47 & 1.01 & 7.27b & 13.64 \\
\hline \multirow{2}{*}{ Aug. 15th } & A & $33.58 b^{*}$ & 34.51 & $0.97^{*}$ & 12.54 & 26.96b \\
\hline & control & $36.27 a$ & 35.71 & 1.02 & 12.67 & 29.49a \\
\hline \multirow{3}{*}{ Aug. 30th } & A & 37.83 & $39.33^{*}$ & 0.96 & $17.01 \mathrm{a}$ & $33.99 a$ \\
\hline & B & $37.62 b^{*}$ & $40.18^{*}$ & 0.94 & $17.50 \mathrm{a}$ & $34.94 a$ \\
\hline & Control & $39.74 a$ & 40.48 & 0.98 & $15.58 b$ & $33.18 b$ \\
\hline \multirow{3}{*}{ Sep. 15th } & A & $41.68 \mathrm{~b}$ & $44.28^{*}$ & 0.94 & 16.88a & $49.59 b$ \\
\hline & B & $41.69 b$ & $45.13^{*}$ & $0.92^{*}$ & $14.69 \mathrm{~b}$ & 56.11a \\
\hline & Control & 43.61a & 45.48 & 0.96 & $17.30 \mathrm{a}$ & $57.08 \mathrm{a}$ \\
\hline \multirow{4}{*}{ Sep. 30th } & A & $43.23 b^{*}$ & $46.41^{*}$ & 0.93 & $18.32 b$ & $63.32 b$ \\
\hline & B & 43.19b & $47.05^{*}$ & 0.92 & $16.82 \mathrm{c}$ & $53.82 c$ \\
\hline & $\mathrm{C}$ & $44.32 \mathrm{a}$ & $47.17^{*}$ & 0.94 & $15.32 d$ & $52.48 c$ \\
\hline & Control & $45.54 \mathrm{a}$ & 47.63 & 0.96 & $20.15 a$ & 73.34a \\
\hline \multirow{4}{*}{ Oct. 15th } & A & $45.72 b$ & 50.03 & 0.91 & 19.98a & 71.83b \\
\hline & B & $45.72 b$ & 50.65 & 0.90 & $18.48 b$ & $64.98 c$ \\
\hline & $\mathrm{C}$ & $47.36 \mathrm{a}$ & $51.60^{*}$ & 0.92 & 18.33b & 68.32bc \\
\hline & Control & $48.75 a$ & 52.29 & 0.93 & 19.96a & $75.98 a$ \\
\hline \multirow{4}{*}{ Nov. 15th } & A & $49.35 b$ & $54.27^{*}$ & 0.91 & $18.32 \mathrm{c}$ & $72.01 b$ \\
\hline & B & 49.37b & $54.87^{*}$ & 0.90 & 19.34b & $70.02 b$ \\
\hline & $\mathrm{C}$ & 50.81a & 56.93 & $0.89^{*}$ & 18.27c & $69.98 b$ \\
\hline & Control & $52.34 a$ & 56.49 & 0.93 & 23.46a & $84.02 \mathrm{a}$ \\
\hline
\end{tabular}

Different small letters mean significant difference at 0.05 levels with different treatments in the same time.

The results showed that film mulching in late July in Jishou region increased soil temperature and decreased soil water potential (Figure 1). It is consistent with the results obtained by Yakushiji et al. [4] and Haiwen Gao et al. [10].

\subsection{The Effect of Film Mulching on Fruit Quality}

During citrus fruit development, film mulching influences the changes of total and reducing sugar content, but different mulching time has different effects. Film mulching during the cell division phage elongated drought stress time and resulted in large change of total sugar content. Film mulching during the cell enlargement period showed lower total sugar content compared to the control. Mulching during the early-mature stage enhanced total sugar content of citrus fruit, which may be due to the increased activity of sucrose synthase (SS) and the reduction of juice $\mathrm{pH}$ caused by slight drought stress. Hence, it improves fruit sink strength [11]. The reducing sugar in Statuma mandarin fruit is mainly glucose and fructose. Mulching during different periods causes different drought stress to citrus and has different effects on reducing sugar content. It may be due to the change of transfer of reducing sugar to citrus juice sacs by osmotic adjustment under drought stress [12].

The studies on the effect of film mulching on citrus organic acid are controversial. Yakushiji et al. [4] and Liming Wu et al. [5] found that film mulching improves the accumulation of citrus organic acid, but Jun Huang et al. [6] revealed that film mulching decreases organic acid content. In addition, Xuegen Shi et al. [8] claimed film mulching has no obvious effect on organic acid accumulation of citrus fruit. In the present study, we found film mulching affected the content of titratable acid in the early stage of fruit development, but the effect was less in the mature stage. The lower titratable acid content (compared to the control) is good for improving fruit taste.

Citrus fruit is an important source for edible Vc. During citrus fruit development, Vc content changed within a small range in the early stage of fruit development. It sharply increased in the late stage of cell enlargement period. Especially, film mulching during the early-mature period made Vc content as high as $153.80 \mathrm{mg} / 100 \mathrm{ml}$, which was significantly higher than the control. The change trend of Vc content is not consistent with the results proposed by Shengnan Shen [13] and Lijuan Wang [14]. The difference may be related to species, climatic conditions, soil elements and other factors, and it needs to be further studied. 
Film mulching affects fruit appearance. The longer the mulching time was, the smaller the fruit size was. The longitudinal and transverse diameters of treated trees were significantly smaller than the controls. The mulching time was not related to the fruit shape index, but in the middle and late stage of fruit development, the index was obviously lower than the control. Film mulching made fruit peel thin, increased soluble solids and made fruit small. However, it did not affect edible rate during fruit mature period. It may be due to the change of endogenous hormones caused by mulching-induced water stress [15].

\section{Conclusion}

Film mulching significantly increases the quality of citrus fruit, but has negative effect on fruit appearance. As to the mulching time, the middle of September is a better time for Jishou region. It is not good to mulch before or after this time. If mulching in July or August, fruit is in the division or enlargement stages. It is bad for fruit growth. If mulching in a late time, it cannot improve fruit quality.

\section{References}

[1] Yan, X.T. and Qi, C.J. (2013) Analysis on International Competitiveness and Growth Effect of Chinese Citrus after Joining WTO. World Agriculture, 1, 71-76.

[2] Zhou, J. (2008) The Effect of Water Content in Red Soil on Ecophysiology of Citrus and Its Mechanisms. Doctoral Thesis, Nanjing Agricultural University, Nangjing.

[3] China Agriplastic Applied Technology Institute (1998) General Technology of Plastic Film Mulching Cultivation. China Agriculture Press, Beijing.

[4] Yakushiji, H., Nonami, H., Fukuyama, T., et al. (1996) Sugar Accumulation Enhanced by Osmoregulation in Satsuma Mandarin Fruit. Journal of the American Society for Horticultural Science, 121, 466-472.

[5] Wu, L.M., Jiang, Y.C., Wang, Z.J., et al. (2009) The Effect of Reflective Film for Mulching Cultivation on Color and Quality of Satsuma Mandarin Fruit. South China Fruits, 38, 39-41.

[6] Huang, J., Zhang, N. and Min, Z.P. (2010) Effect of Mulching Materials on Fruit Quality of Early-Maturing Satsuma Mandarins and Soil Temperature and Moisture of Citrus Orchard. South China Fruit, 39, 15-17.

[7] Wan, Y., Li, C.L., Zou, Y.P., et al. (2011) Effect of Different Facilities on Quality of Ponkan Fruit. Journal of Huazhong Agricultural University, 30, 572-577.

[8] Shi, X.G., Chen, J.W., Xu, H.X., et al. (2011) Effect of Vapor-Permeable Reflective Film Mulching on Quality of Ponkan Fruit. Journal of Fruit Science, 28, 418-422.

[9] Luo, X.Y., Wu, B., Peng, P., et al. (2011) Determining and Analyzing Content of Invert, Reducing and Total Sugar and Vitamin C in Ganzhou Selenium-Rich Navel Oranges. China Food Additives, 4, 203-208.

[10] Gao, H.W., Jiang, N., Liu, Y.Z., et al. (2013) Effects of Film Mulching on Total Soluble Solution, Titratable Acid and Contents of Mineral Elements in Ponkan (Citrus reticulata) Fruit. Journal of Huazhong Agricultural University, 32, 45-49.

[11] Brandon, R.H. and Etxeberria, E.D. (2001) Metabolic Contributors to Drought-Enhanced Accumulation of Sugars and Acids in Oranges. Journal of the American Society for Horticultural Science, 126, 599-605.

[12] Yaknshiji, H., Morinaga, K. and Nonami, H. (1998) Sugar Accumulation and Partitioning in Satsuma Andarin Tree Tissues and Fruit in Response to Drought Stress. Journal of the American Society for Horticultural Science, 123, 719726.

[13] Shen, S.N. (2009) Main Quality Changes of Lane Late and Cara Cara Navel Oranges during Fruit Development. Master Thesis, Huazhong Agricultural University, Huazhong.

[14] Wang, L.J. (2011) Study on the Quality Changes during Fruit Development and Storage of Nanfenmiju. Master Thesis, Huazhong Agricultural University, Huazhong.

[15] Zhao, X.L., Xie, S.X., Lu, X.P., et al. (2013) Effect of Water Stress on Physiological Characteristics, JA Biosynthesis and Correlative Gene Expression in Citrus. Acta Agriculturae Universitatis Jiangxiensis (Natural Sciences Edition), 35, 530-535. 
Scientific Research Publishing (SCIRP) is one of the largest Open Access journal publishers. It is currently publishing more than 200 open access, online, peer-reviewed journals covering a wide range of academic disciplines. SCIRP serves the worldwide academic communities and contributes to the progress and application of science with its publication.

Other selected journals from SCIRP are listed as below. Submit your manuscript to us via either submit@scirp.org or Online Submission Portal.
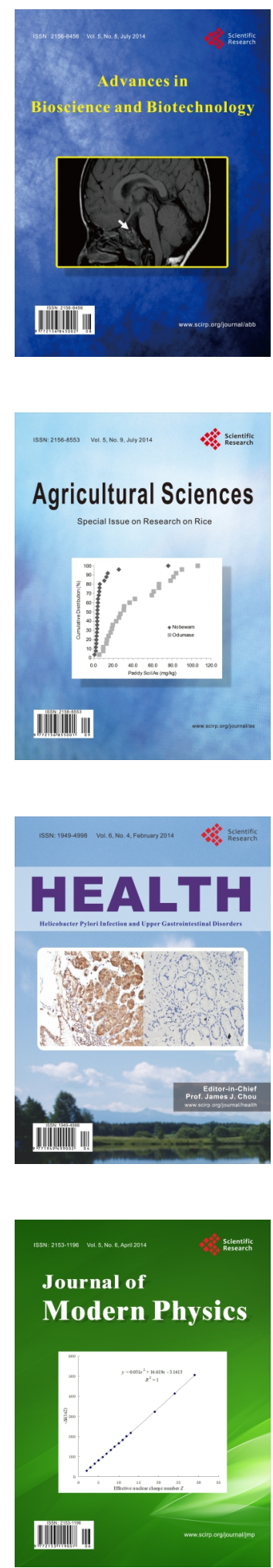
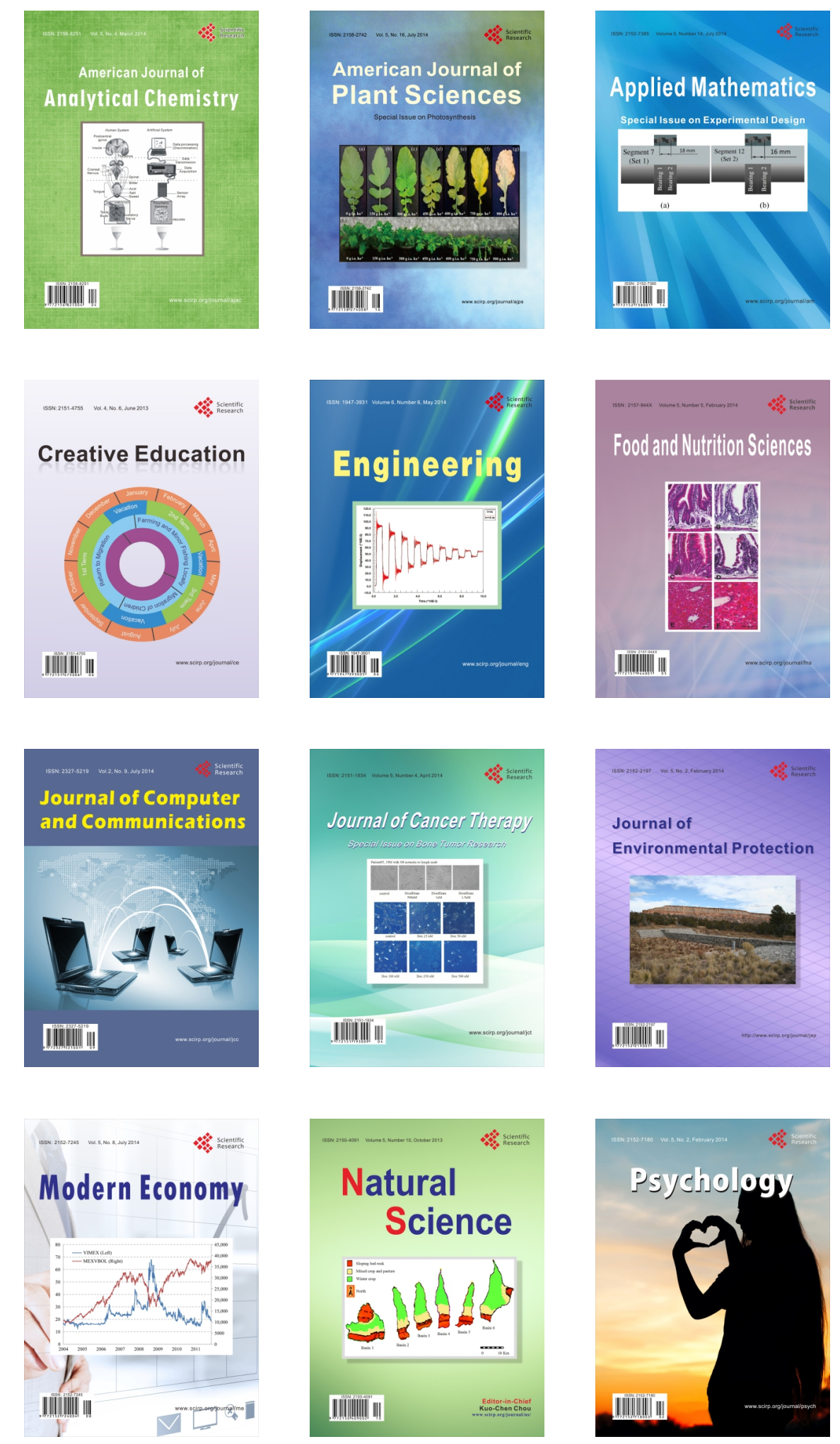